\title{
6
}

\section{Toward a Scholarship of Teaching and Learning in Educational Development}

\author{
Peter Felten \\ Elon University \\ Alan Kalish \\ The Ohio State University \\ Allison Pingree \\ Vanderbilt University \\ Kathryn M. Plank \\ The Ohio State University
}

Educational development traditionally has been a practice-based field. We propose that as a profession we adopt the methods of the scholarship of teaching and learning (SoTL), so often shared with our clients, in order to look through a scholarly lens at the outcomes of our own practice. Using SoTL approaches in our work would deepen the research literature in our field and improve the effectiveness of decisions we make about where to spend limited time and resources. In this chapter, we explore what it might mean for individual developers, and for our professional community, to apply SoTL methods to our practice.

Ficational development (ED) is a profession dedicated to helping colmunities. This field includes all the areas for which we often name it: faculty development; TA development; instructional, academic, and organizational 
development. We have chosen the descriptor educational development rather than any of these other, perhaps more familiar names for the field, because we believe it is the broadest, most inclusive of the available terms. ED professionals work in a range of contexts, from teaching support units to professional development committees. Choosing to name the whole after a part is alienating to those who work in other ways. Although the term educational development is much more common in the UK, Canada, and Australia than the US, we hope it will be adopted more widely as a move to include all of our colleagues within our community.

As a part of this work, especially our work with individual faculty members, many educational developers have recently advocated for and supported a wide range of practices that fall under the rubric of the scholarship of teaching and learning (SoTL) (McKinney, 2004; Schroeder, 2005). Indeed, many teaching centers see SoTL as a central part of their philosophy and offerings. This is so common that in seeking to identify where SoTL is supported within colleges and universities, Huber and Hutchings (2005) identify teaching centers as a "place for good work" (p. 84). Despite this growing engagement with SoTL, however, developers have not done much to use this model to study our own work as developers. In this chapter, we explore what it might mean to do this kind of work. What might it involve and why should we consider doing it? What challenges and opportunities are inherent in pursuing SoTL in ED? In what ways might SoTL in ED draw on, and adapt, frameworks already established through SoTL itself? And what possible future directions emerge through all of these considerations?

\section{SoTL in ED: What and Why?}

Educational development has been a growing field for the last 50 years or so. However, for most of that time it has been a practice-based discipline with litthe in the way of systematic study of its range, its activities, or especially its outcomes. This is not to say that our practice is uninformed by research; in fact, one could make the claim that ED professionals are among the prime scholars of university pedagogies and certainly are major consumers and disseminators of educational research in higher education. But such engagement with educational research is parallel to what Richlin (1993) and Shulman (2000) call "scholarly teaching" as differentiated from the "scholarship of teaching." In their terms, scholarly teaching takes into account the work of others in deciding how to teach, whereas scholarship of teaching engages in structured inquiry into the outcomes of one's teaching practice. In similar 
fashion, many educational developers already perform "scholarly development" by basing their practice on the scholarly literature, but far fewer engage in a scholarship of teaching and learning in development by gathering data on the outcomes of their own work. We believe that our profession would be significantly enhanced if more of us began to apply SoTL methods to our professional practice-conducting systematic and public inquiry about the learning that emerges from practice.

To be more specific, what we know now about the work of educational development comes mainly from a few studies that survey the field, a great deal of local program assessment, and a strong tradition of sharing best practices. Broad studies over time (Centra, 1976; Chism \& Szabo, 1996; Eble \& McKeachie, 1985; Erickson, 1986; Hellyer \& Boschmann, 1993) have offered important ways to outline the evolution and scope of educational development as an emerging field. Most recently, in Creating the Future of Faculty Development, Sorcinelli, Austin, Eddy, and Beach (2006) offer a review of current goals and practices, based on several earlier works and a survey of practitioners. As with previous surveys of the field, Sorcinelli et al. focus on the big picture, the range of practice at many institutions.

At the other end of the spectrum from these broad studies of the profession is program assessment. Most teaching support units regularly collect and analyze data in order to assess their usefulness to their constituencies. However, this analysis is not usually shared beyond the administrative hierarchy of that program. As educational developers, we also have a long and valuable tradition of sharing programs and ideas for practice. The POD publication To Improve the Academy, for example, offers many descriptive pieces on best practices, and the annual $P O D$ conference provides a rich array of practicebased sessions.

These kinds of study-broad surveys of the field, individual program review and assessment, and best practices-are important and useful. They help us understand and describe our work at both the global and local levels. But something is missing: systematic, evidence-based study and publication by practitioners of the outcomes of their practice. This is the same gap that SoTL fills in classroom teaching - the gap between individual practice and higher education research, between anecdotal sharing of best practices and publication of evidence-based scholarship, between individual evaluation of teaching effectiveness and a collective understanding and analysis of learning outcomes. We propose that we adopt the methods of SoTL, which we so often share with our clients, and look through that scholarly lens at our own practice. In so doing, we would be pursuing the same purposes Lee Shulman (2000) outlines for doing SoTL overall: 1) professionalism-recognizing "the 
inherent obligations and opportunities associated with becoming a professional scholar/educator" (p. 49); 2) pragmatism-assuring "that one's work as an educator is constantly improving and meeting its objectives and its responsibilities to students" (p. 49); and 3) policy-providing "the capacity to respond to the legitimate questions" (p. 49) of outside constituents about the quality and value of the work being done.

All three of Shulman's reasons align with the broader goals of the educational development community. In fact, defining the professionalism of ED is the second of the four core goals of the current POD Network Strategic Plan (2005): "to define what professionalization means in the context of POD." In adopting this goal, POD's governing committee identified the same need to recognize and fulfill the "obligations and opportunities associated with becoming a professional" that Shulman identified. Most of the objectives and strategies listed in the plan to meet this goal would be advanced by creating a rich body of scholarship analyzing the learning outcomes of our practice. Such work would serve the pragmatic function of informing our decisions about where best to spend our limited time and resources to achieve our professional mission of helping our colleges and universities function effectively as teaching and learning communities. Finally, Shulman's definition of policy describes a central need of the field of ED: to explain and justify our work as a scholarly area deserving respect in an academic world where such prestige is generally granted to disciplinary research.

\section{Defining SoTL}

So what, more specifically, would doing the SoTL of ED entail? Hutchings (2000, pp. 4-5) describes a taxonomy of questions for SoTL that also could provide a useful model for the SoTL of ED:

- What works?

- What is?

- Visions of the possible

- Formulating a new conceptual framework for shaping thought about practice

Moreover, while SoTL practice varies considerably across disciplines and institutional contexts (Huber \& Hutchings, 2005), all SoTL projects share at least three common components (Hutchings \& Shulman, 1999/2004): 
- SoTL centers on inquiry into learning in a specific context.

- SoTL practitioners conduct inquiries by collecting and analyzing evidence-in other words, SoTL is evidence-based.

- SoTL, like all forms of scholarship, involves the public sharing and critique of both the process and the products of inquiry, and in following ethical standards in doing so.

What follows is a further exploration of how Hutchings's taxonomy, as well as these three components, introduce challenges and opportunities for educational developers attempting to conduct SoTL in ED.

\section{Inquiry}

Most educational developers, as well as our constituents, can quickly think of big questions we have about work in our field: Do the clients we work with become better teachers? Do their students learn more? Such ungainly questions can stymie research, particularly for busy people who have little time for research in the first place. This difficulty is not unique to ED. Many SoTL practitioners struggle to move from interesting but overly broad questions to more manageable but still significant lines of inquiry.

To help faculty new to SoTL focus on questions that are both answerable and evidence based, Georgetown University's Crossroads Online Institute (hosted by the Center for New Designs in Learning and Scholarship) uses a case study linked to a simple but powerful visual. The case explains how Curtis Bennett, a Carnegie scholar, narrowed his inquiry from vague questions about how students think mathematically to more discrete and evidencebased subquestions about the processes students take to learn, and the ways class activities promote mathematical thinking. Bennett found that his subquestions not only were more "doable" as research projects, but also that the results from these focused inquiries provided considerable insight into his larger concerns about mathematical thinking. Figure 6.1, which accompanies Bennett's case, illustrates the connections between overarching questions and progressively more narrow lines of inquiry linked to evidence.

This hierarchy breaks down a general question into component parts, which are further subdivided until specific questions can be tied directly to evidence of learning. The number of layers involved will depend on the nature of the questions and evidence; however, this process typically helps new SoTL practitioners move from broad but ill-defined "what works?" questions to more answerable "what is?" lines of inquiry. 
FIGURE 6.1

Narrowing the Question

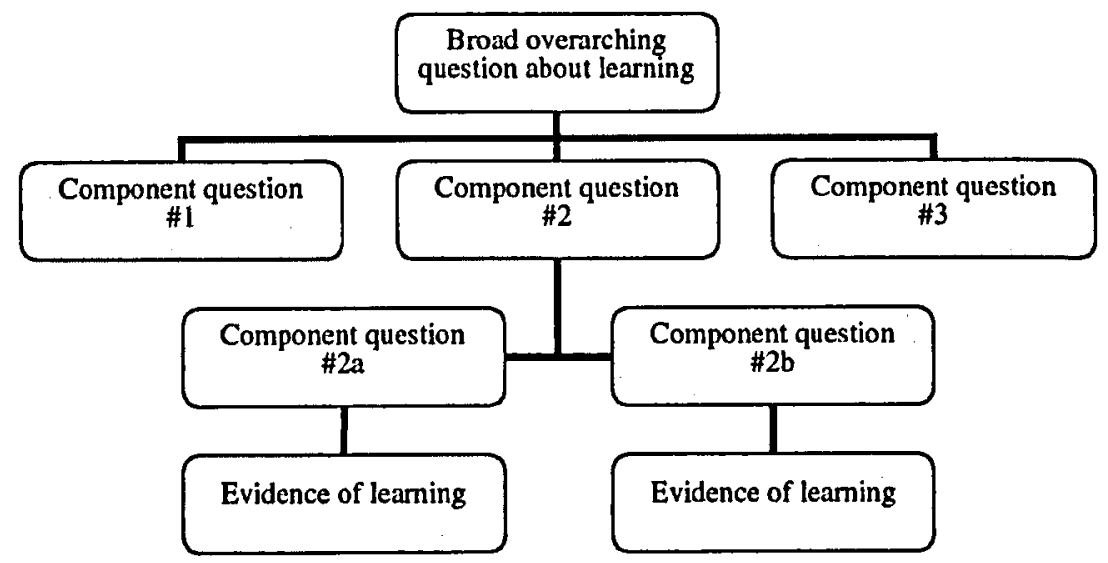

Note. Adapted from: Center for New Designs in Learning and Scholarship, Georgetown University. (n.d.). Narrowing the questions: SoTL case studies. Retrieved May 31, 2006, from http://cndls.georgetown.edu/sotl_module/intro2.html

What might SoTL in educational development look like in practice? If we follow this path, we might, for example, use SoTL approaches to explore the learning that results (or fails to result) from the Small Group Instructional Diagnosis (SGID). Many educational developers use variations on the SGID, a focus group process that gathers student feedback for faculty during a course. Although the SGID is a common tool, relatively little has been written about how it shapes faculty teaching or student learning; instead, articles have tended to offer a guide or step-by-step process approach for educational developers using this technique (Black, 1998; Clark \& Redmond, 1982; Diamond, 2002; Millis, 2004; Snooks, Neely, \& Williamson 2004).

Inquiries into the SGID might explore a range of possibilities along a hierarchy like the one pictured in Figure 6.2.

If we were to approach SGIDs by way of the first three questions in Hutchings's (2000) taxonomy, the lines of inquiry might include the following questions and issues:

- What works? What changes (if any) occur in faculty teaching practice as a result of the SGID process? To probe this question, an educational developer might conduct follow-up interviews with faculty to gather self-report data, and might also analyze course materials (syllabi, assignments, 
FIGURE 6.2

Inquiry About SGIDs

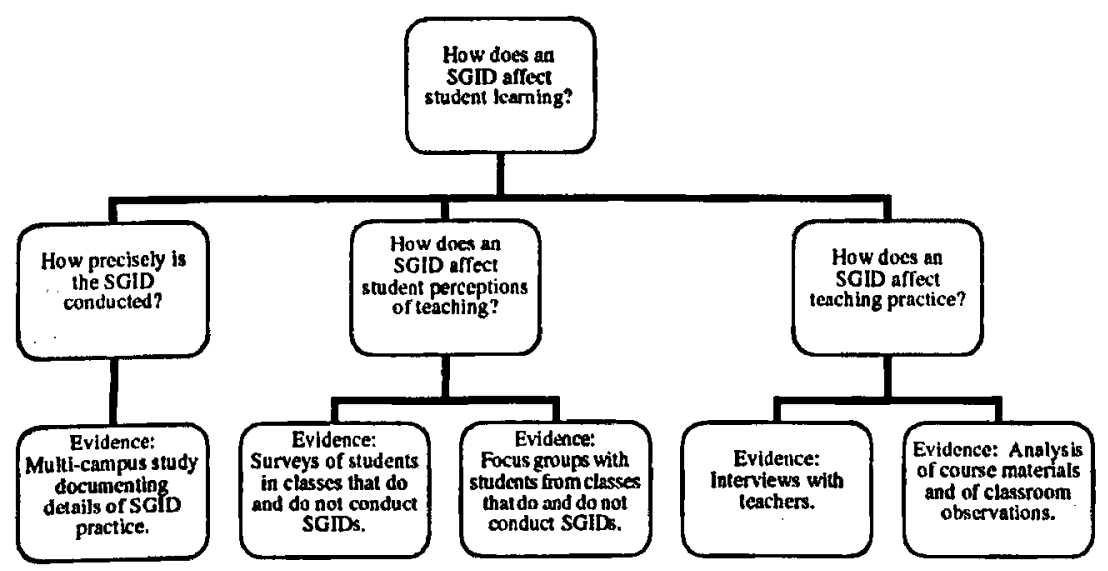

etc.) and conduct classroom observations (either live or on videotape) from before and after the SGID to look for evidence. Such an inquiry might begin with a relatively small sample, since the data gathering and analysis would be intensive. The pilot study then might be used to define the questions and methods for a larger inquiry, perhaps involving educational developers on multiple campuses.

- What is? Educational developers might document SGID practices at a variety of institutions and in a variety of teaching contexts (such as large lecture classes, small seminars, laboratories, or online courses). By collecting specific evidence of the ways SGIDs are conducted, within and across institutional contexts (e.g., How does the educational developer prepare for an SGID? What questions are asked of students? How is the class session conducted? Does the developer drive the discussion toward consensus? How is the student feedback compiled and presented to the instructor?), we might go beyond more generic descriptions into more precise distinctions and variations, and thus to further insights on our individual and collective practice.

- Visions of the possible. How is the SGID transformed if trained students facilitate the process? An inquiry into this question might gather evidence from the faculty and students participating in the SGID (c.g., What perceptions about SGIDs do students and instructors hold before, 
during, and after we do them? How do those perceptions impact the effectiveness of the consultation practice? What changes in those perceptions occur when a student versus a developer facilitates the process?) and also from the student facilitator and the educational developer who trained that student. Observations, interviews, document analysis, and surveys all might provide useful evidence. Findings from this inquiry could open new paths both to educational development practice and to research on student empowerment.

A similar line of inquiry (which emerged in a discussion at a recent POD conference session) following the same taxonomy, this time focusing on educational development workshops, might look something like Figure 6.3. The big questions of our profession (e.g., How does student learning change as a result of our workshops? Our consultations?) are essential to ask, yet essentially impossible to answer on our own. Using SoTL methods to investigate these subquestions can help us grapple with difficult issues in ways that are manageable for both individual and collaborative groups of developers. An SoTL approach, of course, might not be capable of answering all our questions, and we should be wary of pursuing lines of research simply because evidence is available. This approach is not without risks, but the potential of SoTL for educational development, like more traditional SoTL, is transformational: "The scholarship of teaching and learning might then be defined as scholarship undertaken in the name of change, with one measure of its success being its impact on thought and practice" (Hutchings, 2000, p. 8).

\section{FIGURE 6.3}

Inquiry About ED Workshops

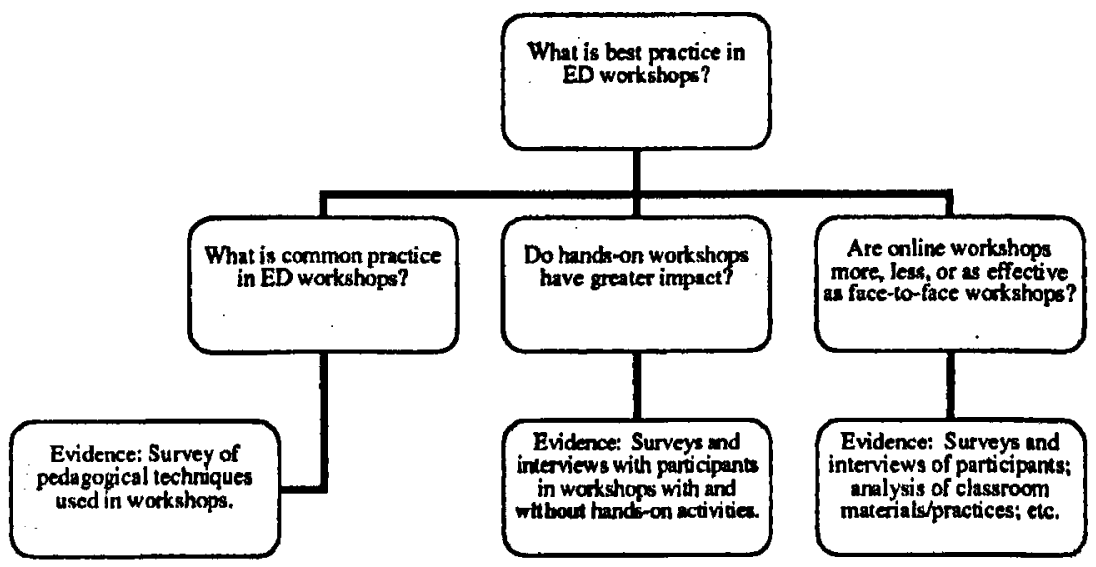




\section{Methods and Evidence}

In gathering the evidence necessary to answer our questions, educational developers will most likely face challenges not unlike those faced by faculty practicing SoTL in the disciplines. Like the vast majority of faculty, most educational developers are not trained as educational researchers. The coauthors of this chapter are an illustrative although not representative sample of educational developers: Three of us have earned a Ph.D. in English, and one in history. How might scholars from the humanities research these questions? What could they contribute to the SoTL of ED? What could they adapt or adopt from other traditions? In Disciplinary Styles in Scholarship of Teaching and Learning, Huber and Morreale (2002) provide many examples of specific disciplinary approaches to SoTL to demonstrate "the virtue of keeping an open mind when looking at the disciplines" (p. 21). They argue that these "very divisions, which some find disturbing, can be sources of strength for the scholarship of teaching and learning" (p. 21). Likewise, educational developers need to take advantage of our disciplinary training and to be open to adapting research methods from other fields (Hutchings, 2000). Over time, a common set of research methods might emerge among the educational development SoTL community; however, we always should cultivate the disciplinary richness of our profession since that will provide new perspectives and approaches to exploring our work (Huber \& Hutchings, 2005).

In addition, like many faculty who practice SoTL, most educational developers also will not have large sample sizes or ample direct evidence for our studies. Rather than abandoning our inquiries, however, we can adopt the classroom research approach advocated by Cross and Steadman (1996), a typical move in SoTL. As Huber and Hutchings (2005) argue, a small sample can be enlightening if the right question is asked, the evidence is collected systematically, and the analysis is rigorous. Similarly, multiple streams of indirect evidence can be helpful when considering questions that are difficult to answer outside of an experimental lab. Indeed, trying to find the holy grail of evidence (large sample, direct evidence, clean data, etc.) can lead us astrayeither by taking our focus off the point of our inquiry (to something answerable but not meaningful) or by pushing us to use research methods far outside our disciplinary training.

An added challenge for the SoTL of ED is that, while SoTL seems to assume some level of continuous contact with students, that longitude may be difficult to achieve for educational developers. Someone may come to just one workshop or do just one consultation over the course of several years. How would we track and study learning in that much more limited context? 
For example, how many consultations would we need to do with the same person or even same set or genre of people (e.g., tenure-track faculty in the humanities) to draw any meaningful conclusions? Cohorts or working groups might offer a more robust opportunity for study-we could see how they change over the course of the cohort and then at a later point. But the wide variations in number of people and consistency of contact could pose an obstacle to drawing many solid conclusions.

With this challenge also comes an opportunity, however. In the SoTL of ED, the "students" whose learning we would study are reflective professionals who have a vested interest in the outcomes of the work and are able to provide analysis as well as data. The SoTL of ED may require transforming the role of the "subject" into someone who collaborates in the larger inquiry. In other words, some of the instructors with whom we work may want to be active co-investigators in projects where we study the ED intervention while they, in turn, investigate the learning outcomes for their students. Even if this parallel model is not used, the professional judgment and reflection of college and university faculty provides us with a very rich source of data. Huber and Hutchings (2005) consider how graduate students can contribute to and be developed by participation in traditional SoTL research; in a similar vein, we contend that partnering with clients (graduate student or faculty) in our SoTL in ED inquiries likely will enhance both the research outcomes and the professional development of all involved.

This is new territory, however, so educational developers will need to be aware of how such relationships might facilitate (or obstruct) SoTL in ED. Through all this, educational developers-like any SoTL practitioners-should

- Focus on questions about learning that most interest and motivate us.

- Define clearly the goals, terms, and methods of our inquiry.

- Collect the best evidence available (though it may be fuzzier than we'd like), relying on research methods that we are trained to use.

- Whenever possible, collect multiple streams of evidence so we can approach a question from multiple perspectives (if several fuzzy pieces of evidence seem to converge, then maybe we're on to something!).

- Go public with our entire research process-inquiry, methods, evidence, and conclusions.

- Recognize the limits of our individual inquiries, and rely on the community of educational developers to build collaborative projects and to reach conclusions that span multiple campuses. 
These procedures and methods should, we believe, lead to useful, structured inquiries into the work of ED.

\section{Ethics}

Sharing our work publicly with this kind of scholarship introduces many ethical considerations. The SoTL of ED makes public detailed information about instructors and possibly students, so there is the potential to do harm. Scholars must comply with the standards of human subjects research. Educational developers should work together with their institutional review boards to clarify expectations and procedures for ensuring that our subjects are protected from harm.

Ethical considerations for SoTL in ED go further, however. Because this kind of research is rooted in practice, it needs to address not just research ethics, but professional ethics as well. For educational developers, the POD Ethical Guidelines (which are reproduced in this volume) outline these ethics. A challenge of SoTL in ED is to conduct research and share the results publicly while still adhering to principles of practice in those guidelines, such as "maintain appropriate boundaries in the relationship, avoid exploiting the relationship in any way, and be clear with themselves and their clients about their specific role" and "protect all privileged information, obtaining informed consent from clients before using or referring publicly to client cases in such a way that the client could be identified" (Professional and Organizational Development Network, 2002).

This challenge is similar to that faced by any instructor conducting SoTL. Just as a faculty member conducting SoTL plays a dual role as both teacher and researcher, an educational developer plays a dual role in conducting SoTL in ED, which complicates the ethical questions involved. For example, standard practice for human subjects research requires consent from the subjects. But in the client/consultant relationship, what would this consent look like? When would we ask for it? How would it affect both our research and our practice if we ask for consent when we first meet a client, before providing any services at all? What impact would asking for consent part way through an ongoing consultative relationship have? And how can we guarantee that a client feels free to say no? We may not like to think that there are power dynamics in our relationships with our clients, but there are, so we must consider how power and perceptions of power might affect the granting of consent. 
In addition to protecting the client, we must also think about how we can ensure that our research does not impair our practice. Our work with clients depends on establishing trust. Will using them as research subjects affect that trust? Will it make us less able to provide service? That is, might the SoTL research process not only consume our precious time but also sap our ability to adapt to client needs? To be effective in consultations, for instance, consultants need to be flexible, interactive, and improvisational. How might we codify, structure, track, and evaluate those kinds of qualities? Put another way, how might we rigorously study and understand those kinds of interactions (and the learning that ensues from them) without draining or overlooking their core vitality?

In Ethics of Inquiry: Issues in the Scholarship of Teaching and Learning, Pat Hutchings (2002) uses case studies to explore questions like these as they pertain to traditional SoTL. She reassures us that "there's no single right way to resolve the ethical dilemmas that arise when investigating classroom practice; indeed, the most important resource may be awareness and reflection" (p. 4). Likewise, there are no simple answers to these questions for SoTL in ED. We can borrow models and strategies from related disciplines, but awareness, reflection, and discussion with our peers is essential. Just as it was suggested earlier that collaboration with peers is one way to broaden the scope of SoTL in ED projects, ongoing discussion of the ethical issues involved also can help us create and refine community standards of practice.

The POD Ethical Guidelines describe educational developers as having "a unique opportunity and a special responsibility to contribute to the improvement of the quality of teaching and learning in higher education." Perhaps a final ethical question to consider is whether or not part of that responsibility is to be as scholarly as possible in the work we do. That is, while there are ethical dilemmas in conducting such research, there may be a bigger dilemma if we do not. SoTL in ED may complicate our roles and our practice, but it may also inform them, enhance them, and in the long run, help us better fulfill our mission to improve the quality of teaching and learning.

\section{Looking to the Future}

Educational developers can and should advance our practice and extend our scholarship by applying SoTL to our own work. By doing so, we will be doing as Lee Shulman (2000) suggests-recognizing and fulfilling the "inherent obligations and opportunities associated with becoming a professional" (p. 49) in our discipline. ED is a part of the larger field of higher education, where 
professions and professionalism are regularly defined and judged by scholarly standards. We believe that SoTL in ED, in turn, will build our "capacity to respond to... legitimate questions" (Shulman, 2000, p. 49) about the quality and value of our work, highlighting it as a scholarly area deserving respect in academe. Such work can do more than address anxieties about prestige. Expanding the research literature on ED practices can improve greatly the effectiveness of decisions about where to spend limited time and resources. This should improve our ability to achieve our professional mission of helping our colleges and universities to function effectively as teaching and learning communities.

Of course, our exploration leads to more questions than we can answer here. If and as the profession of educational development does adopt the SoTL model, we also will need to address the following issues (and many others):

- What are the intersections between the core components of our practice and our institutional contexts? Sorcinelli et al.'s (2006) survey identifies these core components: individual consultations, orientations, workshops and programs, grants and awards, resources and publications, special services. Do all components of practice work equally well in all institutional contexts? Which best practices transcend institutional type, and which ones need to be honed more finely?

- How will SoTL in ED be supported and rewarded? Many questions about rewards and incentives have emerged for faculty doing SoTL (Huber, 2004). How might similar issues apply to educational developers? What is the appropriate trade-off for ED professionals between doing our practice and researching our practice? Are those two in opposition, or should they be integrated? How does SoTL in ED align with our reward structures-within our field, at our local institutions, and in our own personal development as professionals? Do we, like traditional SoTL, need to be advocating for new or revised systems to evaluate and recognize our scholarly work?

- Should SoTL in ED be built on a collaborative foundation? Randy Bass recently raised important questions about the value of individual SoTL research (Bernstein \& Bass, 2005). Although welcoming all levels of SoTL practice, Bass calls for "an entirely different developmental model" ( $p$. 42) that involves groups inquiring jointly into common questions. This, Bass contends, might permit SoTL to answer essential questions that are difficult to address through individual research alone. Educational development has a strong professional history of cooperation and sharing. 
How might we leverage this tradition to create a new model of SoTL research that will produce knowledge capable of transforming both our individual practice and our profession?

These questions are beyond the scope of this chapter; indeed, they are beyond the ability of any member of our profession to answer alone. However, ED has a long tradition of sharing effort and working in community. As we go forward, we are confident that with awareness, reflection, and discussion in community, these questions-and the many others we have not yet identified-can be explored to the benefit of all.

\section{References}

Bernstein, D., \& Bass, R. (2005, July/August). The scholarship of teaching and learning. Academe, 9l(4), 37-43.

Black, B. (1998). Using the SGID method for a variety of purposes. In M. Kaplan \& D. Lieberman (Eds.), To improve the academy: Vol. 17. Resources for faculty, instructional, and organizational development (pp. 245-262). Stillwater, OK: New Forums Press.

Centra, J. A. (1976). Faculty development practices in U.S. colleges and universities. Princeton, NJ: Educational Testing Service.

Chism, N. V. N., \& Szabo, B. (1996). Who uses faculty development services? In L. Richlin \& D. DeZure (Eds.), To improve the academy: Vol. 15. Resources for faculty, instructional, and organizational development (pp. 115-128). Stillwater, OK: New Forums Press.

Clark, D. J., \& Redmond, M. (1982). Small group instructional diagnosis: Final report. Seattle, WA: University of Washington, Department of Biology Education. (ERIC Document Reproduction Service No. ED217954)

Cross, K. P., \& Steadman, M. H. (1996). Classroom research: Implementing the scholarship of teaching. San Francisco, CA: Jossey-Bass.

Diamond, N. A. (2002). Small group instructional diagnosis: Tapping student perceptions of teaching. In K. H. Gillespie, L. R. Hilsen, \& E. C. Wadsworth (Eds.), A guide to faculty development: Practical advice, examples, and resources (pp. 82-91). Bolton, MA: Anker.

Eble, K. E., \& McKeachie, W. J. (1985). Improving undergraduate education through faculty development: An analysis of effective programs and practices. San Francisco, CA: Jossey-Bass. 
Erickson, G. (1986). A survey of faculty development practices. In M. Svinicki, J. Kurfiss, \& J. Stone (Eds.), To improve the academy: Vol. 5. Resources for faculty, instructional, and organizational development (pp. 182-196). Stillwater, OK: New Forums Press.

Hellyer, S., \& Boschmann, E. (1993). Faculty development programs: A perspective. In D. L. Wright \& J. P. Lunde (Eds.), To improve the academy: Vol. 12. Resources for faculty, instructional, and organizational development (pp. 217-224). Stillwater, OK: New Forums Press.

Huber, M. T. (2004). Balancing acts: The scholarship of teaching and learning in academic careers. Sterling, VA: Stylus.

Huber, M. T., \& Hutchings, P. (2005). The advancement of learning: Building the teaching commons. San Francisco, CA: Jossey-Bass.

Huber, M. T., \& Morreale, S. P. (Eds.). (2002). Disciplinary styles in the scholarship of teaching and learning: Exploring common ground. Washington, DC: American Association for Higher Education.

Hutchings, P. (2000). Introduction: Approaching the scholarship of teaching and learning. In P. Hutchings (Ed.), Opening lines: Approaches to the scholarship of teaching and learning (pp. 1-10). Menlo Park, CA: Carnegie Foundation for the Advancement of Teaching.

Hutchings, P. (Ed.). (2002). Ethics of inquiry: Issues in the scholarship of teaching and learning. Menlo Park, CA: Carnegie Foundation for the Advancement of Teaching.

Hutchings, P., \& Shulman, L. S. (2004). The scholarship of teaching: New elaborations, new developments. In L. S. Shulman, Teaching as community property: Essays on higher education (pp. 145-154). San Francisco, CA: Jossey-Bass. (Original work published 1999)

McKinney, K. (2004). The scholarship of teaching and learning: Past lessons, current challenges, and future visions. In C. M. Wehlburg \& S. Chadwick-Blossey (Eds.), To improve the academy: Vol. 22. Resources for faculty, instructional, and organizational development (pp. 3-19). Bolton, MA: Anker.

Millis, B. J. (2004). A versatile interactive focus group protocol for qualitative assessments. In C. M. Wehlburg \& S. Chadwick-Blossey (Eds.), To improve the academy: Vol. 22. Resources for faculty, instructional, and organizational development (pp. 125-141). Bolton, MA: Anker.

Professional and Organizational Development Network in Higher Education. (2002). Ethical guidelines for educational developers. Retrieved June 2, 2006, from http://podnetwork.org/development/ethicalguidelines.htm 
Professional and Organizational Development Network in Higher Education. (2005). The POD Network strategic plan 2005. Retrieved June 2, 2006, from www.podnetwork.org/pdf/PODplan.pdf

Richlin, L. (Ed.). (1993). New directions for teaching and learning: No. 54. Preparing faculty for the new conceptions of scholarship. San Francisco, CA: Jossey-Bass.

Schroeder, C. M. (2005). Evidence of the transformational dimensions of the scholarship of teaching and learning: Faculty development through the eyes of SoTL scholars. In S. Chadwick-Blossey \& D. R. Robertson (Eds.), To improve the academy: Vol. 23. Resources for faculty, instructional, and organizational development (pp. 47-71). Bolton, MA: Anker.

Shulman, L. S. (2000, April). From Minsk to Pinsk: Why a scholarship of teaching and learning? Journal of the Scholarship of Teaching and Learning, 1(1), 48-52.

Snooks, M. K., Neely, S. E., \& Williamson, K. M. (2004). From SGID and GIFT to BBQ: Streamlining midterm student evaluation to improve teaching and learning. In C. M. Wehlburg \& S. Chadwick-Blossey (Eds.), To improve the academy: Vol. 22. Resources for faculty, instructional, and organizational development (pp. 110-124). Bolton, MA: Anker.

Sorcinelli, M. D., Austin, A. E., Eddy, P. L., \& Beach, A. L. (2006). Creating the future of faculty development: Learning from the past, understanding the present. Bolton, MA: Anker. 